\title{
Inter-trip links incorporated optimal protection coordination
}

\author{
Ali Abbasi, Hossein Kazemi Karegar, Tohid Soleymani Aghdam
}

Faculty of Electrical Engineering, Shahid Beheshti University, Tehran, Iran

\begin{tabular}{l} 
Article Info \\
\hline Article history: \\
Received Mar 23, 2019 \\
Revised Aug 13, 2019 \\
Accepted Aug 29, 2019 \\
\hline
\end{tabular}

\section{Keywords:}

Distribution network Genetic algorithm Inter-trip link OverCurrent relays Protection coordination

\begin{abstract}
Due to advances in smart grid, different communication links as delay, intertrip and activation are used between relays to enhance the protection system performance. In this paper, the effect of inter-trip links on optimal coordination of directional overcurrent relays (DOCRs) is analytically investigated and modelled. Moreover, an index is proposed to find the optimum locations for inter-trip link installation to reach the minimal fault clearance times under the selectivity constraint. Then a method is proposed to determine the candidate locations of inter-trip links and the associated reduced operating times. An Exhaustive search approach is also used to validate the efficiency of the proposed method. The method is simulated and tested on distribution network of IEEE 33 bus using the Power Factory software and MATLAB optimization toolbox. Genetic algorithm is used as an optimization tool to find optimal settings of relays. The results indicate the capability of proposed method in optimal protection coordination with optimum inter-trips.
\end{abstract}

Copyright $\odot 2020$ Institute of Advanced Engineering and Science. All rights reserved.

\section{Corresponding Author:}

Hossein Kazemi Karegar, Faculty of Electrical Engineering, Shahid Beheshti University, Evin, Shahriyari Squarer, Tehran, Iran. Email: h_kazemi@sbu.ac.ir

\section{INTRODUCTION}

Protection coordination tries to design a sensitive protection under the selectivity constraint. Optimal coordination of DOCRs can be formulated as an optimization problem. Several deterministic and heuristic methods such as simplex, particle swarm optimization, genetic algorithm and harmony search algorithm are proposed in the literature to find the optimum relay settings [1-6].

Nowadays and due to advances in communication infrastructures related to smart grid, communication-assisted protection scheme has been received attention to be applied in distribution networks. In communication-assisted protection systems, different links as delay, block, inter-trip and differential scheme are used to improve the DOCRs performance. Differential protection is also reviewed attention due to low fault current contribution of inverter-based distributed generation.

Differential protection is generally used for microgrid protection due to low short circuit currents in islanded mode of operation [7-11]. Different communication tools as power line carrier [9] and fiber optics are used. In [12-14] differential protection is used for distribution network protection to cope with different short circuit levels. In [12] hybrid differential adaptive protection is used for where in case of communication failure, the differential relays changes their role to adaptive overcurrent ones. Multi-layer differential scheme is also proposed to provide the backup protection [13-15].

Adaptive protection where the data is exchanged from a central unit to the DOCRs in non-fault condition is becoming popular due to uncertainties in distribution grids. In adaptive protection, due to changes in grid structure or connection status of distribution generation, the new settings of relays are calculated offline [16-18] or online [19-21] and then transmitted to the relays. 
Data exchange between relays during the faulted period can be performed as inter-trip, delay and block. In [22] simple definite time relays with delay and block signals on GOOSE bed is used for islanded distribution grid. Similar idea with two definite time settings along with delay and inter-trip is used in [23]. In [24] delay signals is used for fault clearance time reduction and stable operation of low inertia distributed generations. Bidirectional relays with block signals are introduced in [25] where all relays are communicating during the fault for both sensitivity and selectivity. This work is completed in [24] as only the candidate relays act bidirectional to minimize the required data network.

As the authors' knowledge, the relays optimal coordination problem is not investigated in presence of inter-trip links. Inter-trip links are used to achieve to fast fault clearance on the applied protective zone, indirectly affecting the other relays operation times. In this paper, concept of inter-trip incorporated protection coordination is introduced and the required formula is developed. Moreover, inter-trip impact on protection coordination is investigated and modeled. Finally, a new method based on introduced index is proposed to find the optimum locations for inter-trip installation with the goal of reduction in fault clearance time. The paper is organized as follows. The next section describes the conventional protection coordination. Inter-trip modeling and the proposed method are explained in section 3. Section 4 represents the simulation results for different scenarios.

\section{OPTIMAL PROTECTION COORDINATION}

The optimal protection coordination can be formulated as an optimization problem with an objective function stated in (1).

$$
\operatorname{Min} T=\sum_{f=1}^{f_{n}} \sum_{i=1}^{n} t_{i, f_{i}}
$$

Where $f$ indicates the near-end and far-end faults, $i$ represents primary relay indices and $t_{i, f_{i}}$ is the operating time of primary relay $i$ for a near/far end fault $f_{i}$.

To ensure the selectivity of the protection system, the operating time of backup relay should lag enough, as Coordination Time Interval (CTI). The coordination constraint is shown in (2). The typical value of CTI lies in range of 200-300 ms. $j$ is the backup relay indices and $t_{j}$ is the operating time of backup relay.

$$
t_{j}-t_{i} \geq \text { CTI for all } f_{i}
$$

The operating time of DOCR is given by (3) as follows

$$
t=\frac{A}{\left(\frac{f}{I_{p}}\right)^{B}-1} T D S
$$

Where $I_{f}$ is the fault current seen by the relay, TDS is relay Time Dial Setting (TDS) and $I_{p}$ is the relay pick up current. Constants $A$ and $B$ define the relay curve type. The relay $I_{p}$ and TDS are bounded as below.

$$
\begin{aligned}
& T D S_{\min } \leq T D S \leq T D S_{\max } \\
& I_{p \min } \leq I_{p} \leq I_{p \max }
\end{aligned}
$$

\section{INTER-TRIP INCORPORATED PROTECTION COORDINATION}

Inter-Trip link is used between relays at both ends of a line where relays are communicating with each other through the link. The link can be in form of power line carrier, pilot wires and optical fibers. A simple inter-trip link between the relays is shown in Figure 1, where relays $R_{a}$ and $R_{b}$ are exchanging data through the dedicated link.

The main goal of using inter-trip links is to reduce the fault clearance time. Operation principle of inter-trip link can be explained as follows. Once a fault like $F_{1}$ occurs in the main protection zone of relays $R_{a}$ and $R_{b}$, they pick up the fault current. When the relays picked up for duration, they send each other the pickup activation signal. Since the no synchronous data measurement and transmission is required and low data rate is transferred, the inter-trip link requirements are not as strict as differential protection and which results in lower cost. 


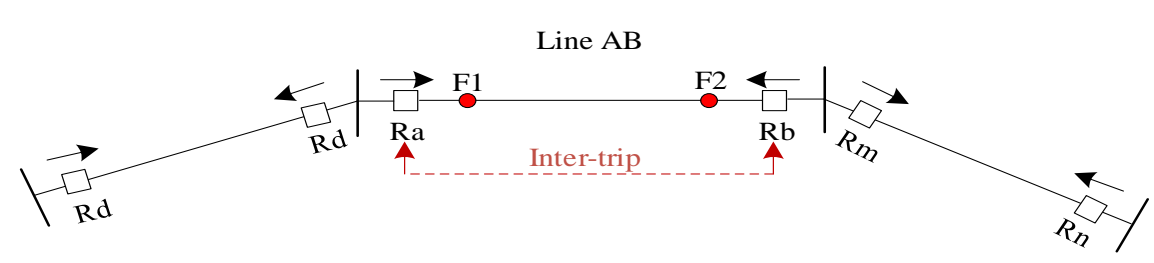

Figure 1. Inter-trip example

The relays $R_{a}$ and $R_{b}$ issue a trip if they pick up the local current and receive a pickup activation signal from the other end relay. The inter-trip is used for quick fault isolation in the relevant line where the operating time associated with relay setting is high. Assuming a minimum pickup duration of $T_{\text {pickup }}$ and the latency and process time as $t_{\text {delay }}$, the trip signal for fault F1 by inter-trip module is as (5).

$$
t_{\text {inter-trip }}=T_{\text {pickup }}+t_{\text {delay }}
$$

The relay tripping time for faults in primary zone as $F_{1}$ and $F_{2}$ incorporating the inter-trip module can be formulated as (6).

$$
\begin{aligned}
& t_{R a}^{*}=\min \left(t_{R a}, t_{\text {inter-trip }}\right) \\
& t_{R b}^{*}=\min \left(t_{R b}, t_{\text {inter-trip }}\right)
\end{aligned}
$$

where $t_{R a}$ and $t_{R b}$ are the tripping time issued by settings and $t_{R a}^{*}$ and $t_{R b}^{*}$ are the overall tripping time of relays considering the inter-trip module. As seen form (6), the overall effect of inter-trip is to decrease the fault clearance time in the relevant line. The effect of inter-trip is dependent on the settings of $R_{a}$ and $R_{b}$ which is obtained through optimal protection coordination. The inter-trip link has two direct and indirect impacts on protection coordination problem which is described as below.

In a meshed grid, it can be assumed that each relay trips the near end fault faster than other relay, which is a realistic assumption. The relay tripping time based on settings can be shown based on as Figure 2(a). The incorporated inter-trip link is illustrated with a constant tripping time for all faults in line $A B$ which is shown by a solid red line. As seen, the inter-trip decreases the fault clearance time in some sections of line AB. The full potential of inter-trip is employed if the $\left.t_{R a}\right|_{f 1}$ and $\left.t_{R b}\right|_{f 2}$ are allocated above the intertrip line as shown in Figure 2(b). This can be formulated as the necessity condition for inter-trip installation as indicated in (7).

$$
t_{\text {inter-trip }} \leq \min \left(\left.t_{R a}\right|_{f 1},\left.t_{R b}\right|_{f 2}\right)
$$
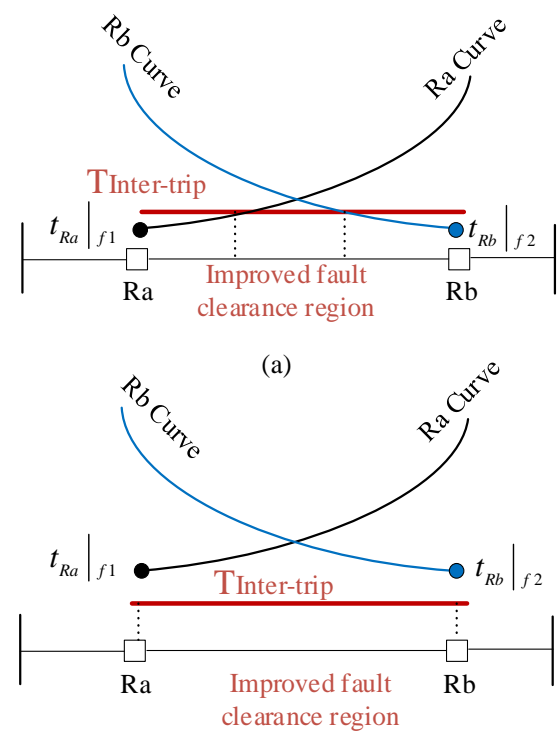

(b)

Figure 2. Direct impact of inter-trip link 
The above mentioned situation expresses the condition for maximum utilization of inter-trip direct impact. As a direct impact, the inter-trip lowers the fault clearance time in line $\mathrm{AB}$ to the $t_{\text {inter-trip }}$. The indirect impact of the inter-trip can be investigated though the Figure 3 where tripping curves of $R_{a}$ and its backup $R_{c}$ are plotted. Due to the inter-trip signal, the tripping curve of $R_{a}$ is modified which is similar to a definite time curve. Due to increased time difference between $R_{a}$ and $R_{c}$, the setting of $R_{c}$ can be modified to achieve more sensitive operation which is also shown. The new settings of $R_{c}$ should satisfy two coordination constraints as below.

As seen, the relay $R_{c}$ settings become more sensitive with applying the inter-trip on line $\mathrm{AB}$ and this phenomena can be generalized to all upstream relays. This is the indirect impact of inter-trip utilization, which results in the operating time reduction of other relays. The new settings of $R_{c}$ should satisfy following constraints considering inter-trip link between $R_{a}$ and $R_{b}$

$$
\begin{aligned}
& \left.t_{R c}^{*}\right|_{f 2}-\left.t_{R a}\right|_{f 2} \geq C T I \\
& \left.t_{R c}^{*}\right|_{f 1}-\min \left(\left.t_{R a}\right|_{f 1}, t_{\text {inter-trip }}\right) \geq C T I
\end{aligned}
$$

Summarizing the mentioned formulas, an index can be used for optimum allocation of inter-trip links to reduce the overall operating times of relays. The proposed index is given in (9) which should be calculated for each line.

$$
\text { Index }=\alpha \times D I+\beta \times I D I
$$

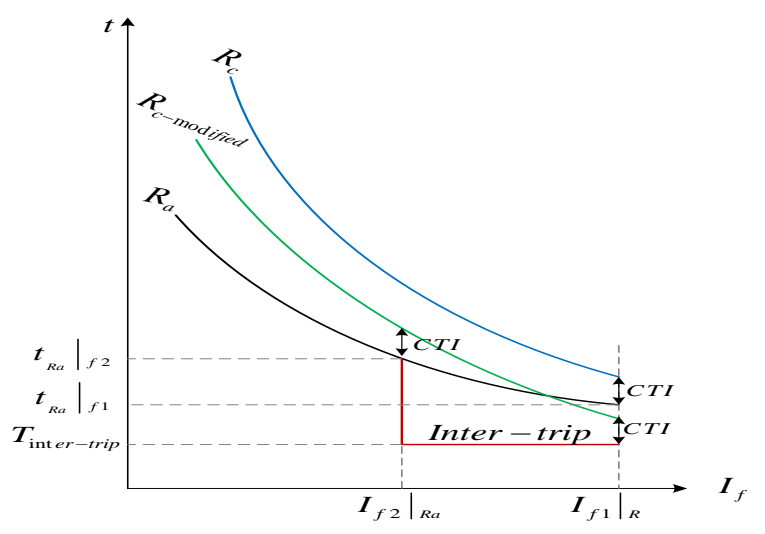

Figure 3. Indirect impact of inter-trip link

where $D I$ and $I D I$ are the direct and indirect impact components of inter-trip installation at a given location. $\alpha$ and $\beta$ are the weighting factors. The $D I$ for line $\mathrm{AB}$ in Figure 1 can be calculated as in (10).

$$
\begin{aligned}
& D I_{F 1}=\left.t_{R a}\right|_{f 1}-\min \left(\left.t_{R a}\right|_{f 1}, t_{\text {inter-trip }}\right)+\left.t_{R b}\right|_{f 1}-\min \left(\left.t_{R b}\right|_{f 1}, t_{\text {inter-trip }}\right) \\
& D I_{F 2}=\left.t_{R a}\right|_{f 2}-\min \left(\left.t_{R a}\right|_{f 2}, t_{\text {inter-trip }}\right)+\left.t_{R b}\right|_{f 2}-\min \left(\left.t_{R b}\right|_{f 2}, t_{\text {inter-trip }}\right) \\
& D I=D I_{F 1}+D I_{F 2}
\end{aligned}
$$

The IDI reflects the sensitivity increase in neighbor relays i.e. backup relays of $R_{d}$ and $R_{n}$, where it can be calculated considering the (7) and Figure 1. IDI should be calculated for each relay as shown in (11).

$$
I D I=\gamma \times \sum_{n=1}^{N_{b}}\left(\left.t_{\text {backup }}\right|_{f a r}-\left.t_{\text {primary }}\right|_{\text {far }}\right)
$$

where $\gamma$ is a binary coefficient to exclude backup relays with no operating time reduction and $N_{b}$ is total number of backup relays. Two conditions should be reached for IDI being nonzero. First, the relevant $D I$ term should be nonzero and the coordination constraint should be a binding constraint. In case of zero DI of primary relay for near end fault, the backup relay cannot become more sensitive as shown in Figure 3. Moreover, in case of non-binding constraint, the setting of the backup relay is dictated with other relays not the relays with inter-trip. $\gamma$ is described as (12). 


$$
\gamma=\left\{\begin{array}{cc}
0 & \text { non }- \text { binding constraint } \\
0 & \left.t_{\text {primary }}\right|_{\text {near }}-t_{\text {inter-trip }} \leq 0 \\
1 & \text { else }
\end{array}\right.
$$

The proposed method for optimal inter-trip allocation is depicted in Figure 4. At initial step, optimal coordination of relays is performed. Then the proposed index is calculated for all lines. The inter-trip is modeled and the best location is selected according to the propose index. Then protection coordination is run again to re-calculate the index for next inter-trip location. This process continues until the all locations for the known number of inter-trips are found.

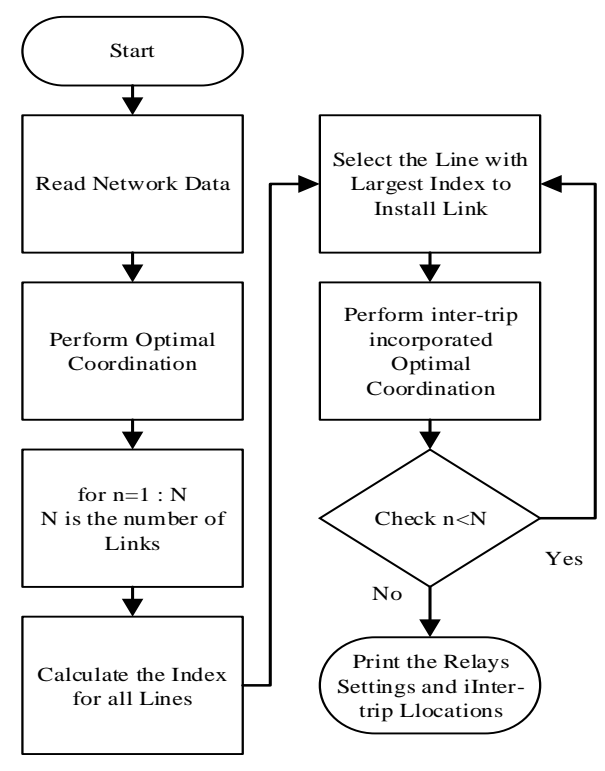

Figure 4. Flowchart of proposed algorithm

\section{SIMULATION RESULTS AND DISCUSSIONS}

The proposed method for optimum inter-trip link allocation with optimal protection coordination is tested on modified IEEE 30 bus network. IEEE 30 bus is composed of sub-transmission and distribution networks where the distribution part is studied here which is shown in Figure 5. Three DGs are added to form an active distribution network. As seen, 43 DOCRs are used to isolate the faults and very inverse curve is assumed for all DOCRs. Different scenarios are simulated to present the capability of the proposed method. Genetic algorithm is used as an optimization tool for optimal protection coordination.

Scenario A, no inter-trip link: In this scenario, no inter-trip link is used and the conventional protection coordination is performed for the case study grid. The genetic algorithm convergence during the optimization process is shown in Figure 6. The total operating time is $31.6958 \mathrm{~s}$ and the optimal settings of relays are listed in Table 1.

Scenario B, single inter-trip link: In this scenario, exhaustive search and the proposed index are used to determine the best location for single inter-trip location. The proposed index is calculated using the previous settings to find best location for the inter-trips. Table 2 lists the five most appropriate candidates for inter-trip location calculated by proposed method and the exhaustive search. As seen the line R25R26 is the best candidate location to install the inter-trip. The results of exhaustive validates the capability of proposed method where same priority list is found by both proposed and exhaustive search method. The optimal settings of relays with an inter-trip link installed on R25R26 are listed in Table 3. There is about $2.5 \mathrm{~s}$ reduction in total operating time of relays. As seen, the neighbor relays settings became more sensitive. For example the R28 pickup current is decreased from 0.342 to 0.2743 and the TDS is remained constant.

Scenario C, three inter-trip link installations: In this scenario, the proposed method in flowchart is run to find the optimum locations of three inter-trip links. The proposed method assigned the links to the R25R26, R7R8 and R13R14. Protection coordination considering the installed inter-trips are performed where the obtained optimal settings of relays is reported in Table 4. Total operating time is decreased from 31.56 to $25.57 \mathrm{~s}$ due to installed three inter-trip links. Table 5 represents relays operating times for some near-end faults based on settings obtained in scenario $\mathrm{C}$. 


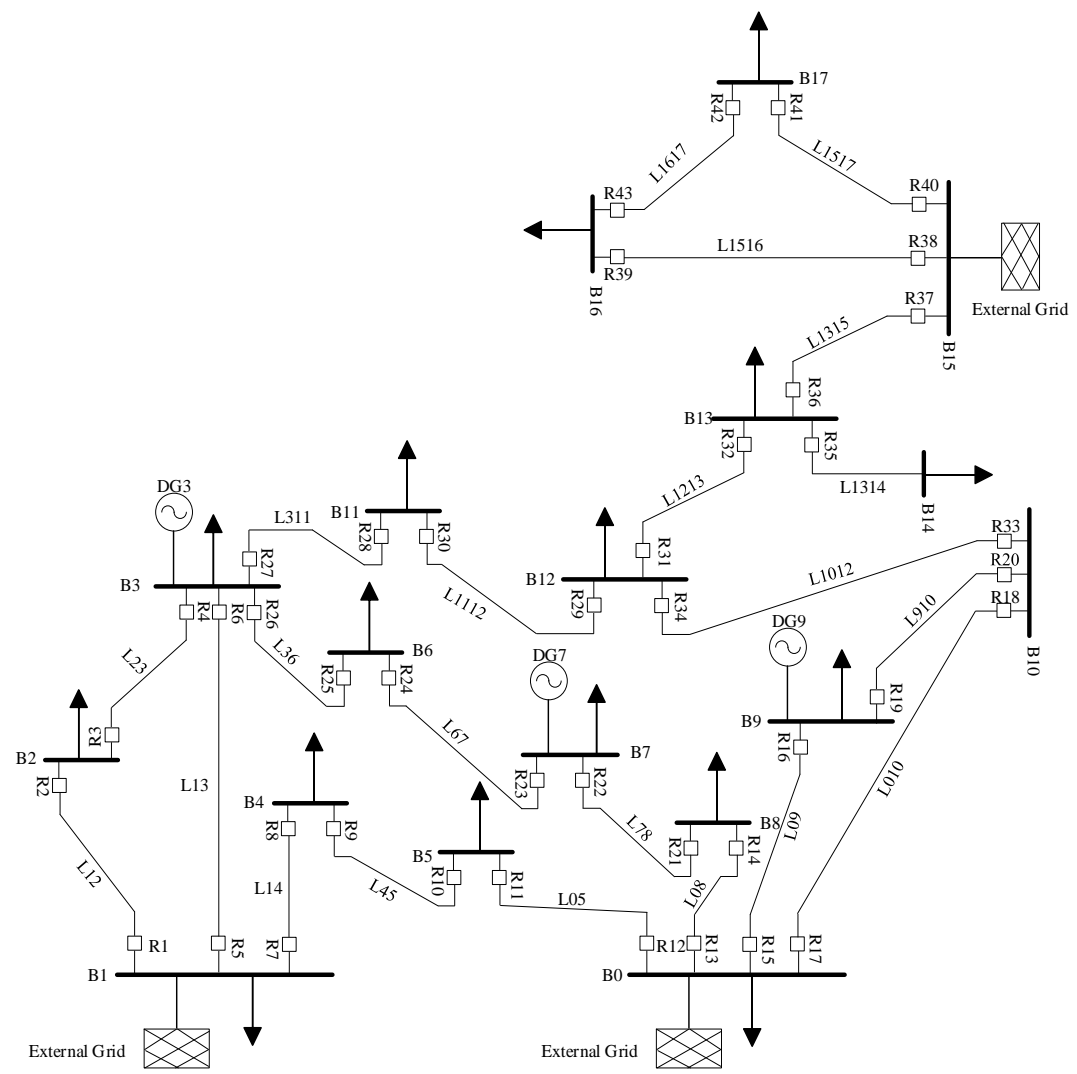

Figure 5. Case study network

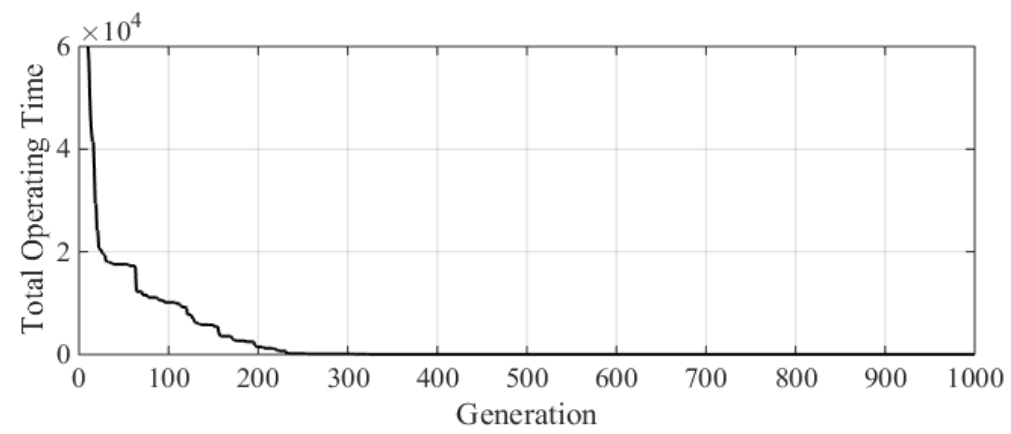

Figure 6. Convergence of genetic algorithm for scenario A

Table 1. Optimal setting of relayes for scenario A

\begin{tabular}{ccccccccc}
\hline Relay No. & Ip $(\mathrm{pu})$ & TDS & Relay No. & Ip(pu) & TDS & Relay No. & Ip(pu) & TDS \\
\hline R1 & 0.2223 & 0.3494 & R16 & 0.208 & 0.2608 & R31 & 0.5117 & 0.1101 \\
R2 & 0.1132 & 0.1298 & R17 & 0.123 & 0.6547 & R32 & 0.305 \\
R3 & 0.0652 & 0.5435 & R18 & 0.1034 & 0.4023 & R33 & 0.2893 \\
R4 & 0.0894 & 0.5991 & R19 & 0.1458 & 0.8247 & R34 & 0.3044 & 0.3223 \\
R5 & 0.4251 & 0.3128 & R20 & 0.1486 & 0.6248 & R35 & 0.0991 & 0.0528 \\
R6 & 0.3058 & 0.2048 & R21 & 0.1933 & 0.7909 & R36 & 0.3802 \\
R7 & 0.2925 & 0.5876 & R22 & 0.1261 & 0.9105 & R37 & 0.3878 \\
R8 & 0.4342 & 0.0878 & R23 & 0.2049 & 0.7138 & R38 & 0.1706 \\
R9 & 0.2101 & 0.5722 & R24 & 0.2865 & 0.3774 & R39 & 0.1601 \\
R10 & 0.2128 & 0.3909 & R25 & 0.184 & 0.5945 & R40 & 0.2734 \\
R11 & 0.3108 & 0.2683 & R26 & 0.171 & 0.9306 & R41 & 0.138 \\
R12 & 0.3406 & 0.468 & R27 & 0.1599 & 0.7636 & R42 & 0.1632 \\
R13 & 0.2116 & 0.9597 & R28 & 0.342 & 0.1175 & R43 & 0.0501 \\
R14 & 0.1631 & 0.457 & R29 & 0.1521 & 0.5047 & Total Operating Time & 0.1693 \\
R15 & 0.3106 & 0.4954 & R30 & 0.2402 & 0.2913 & 31.6958 \\
\hline
\end{tabular}


Table 2. Five most appropriate candidates for inter-trip location

\begin{tabular}{cccc}
\hline \multicolumn{2}{c}{ Proposed Method } & \multicolumn{2}{c}{ Exhaustive search } \\
Line & Index value & Inter-trip location & $\begin{array}{c}\text { Operating time } \\
\text { obtained by GA. }\end{array}$ \\
\hline R25R26 & 2.84976 & R25R26 & 28.9694 \\
R13R14 & 2.31074 & R13R14 & 29.5619 \\
R23R24 & 1.94092 & R23R24 & 29.5905 \\
R21R22 & 1.85686 & R21R22 & 29.8624 \\
R9R10 & 1.23856 & R9R10 & 30.3784 \\
\hline
\end{tabular}

Table 3. Optimal settings of relayes for scenario B: inter-trip on line R25R26

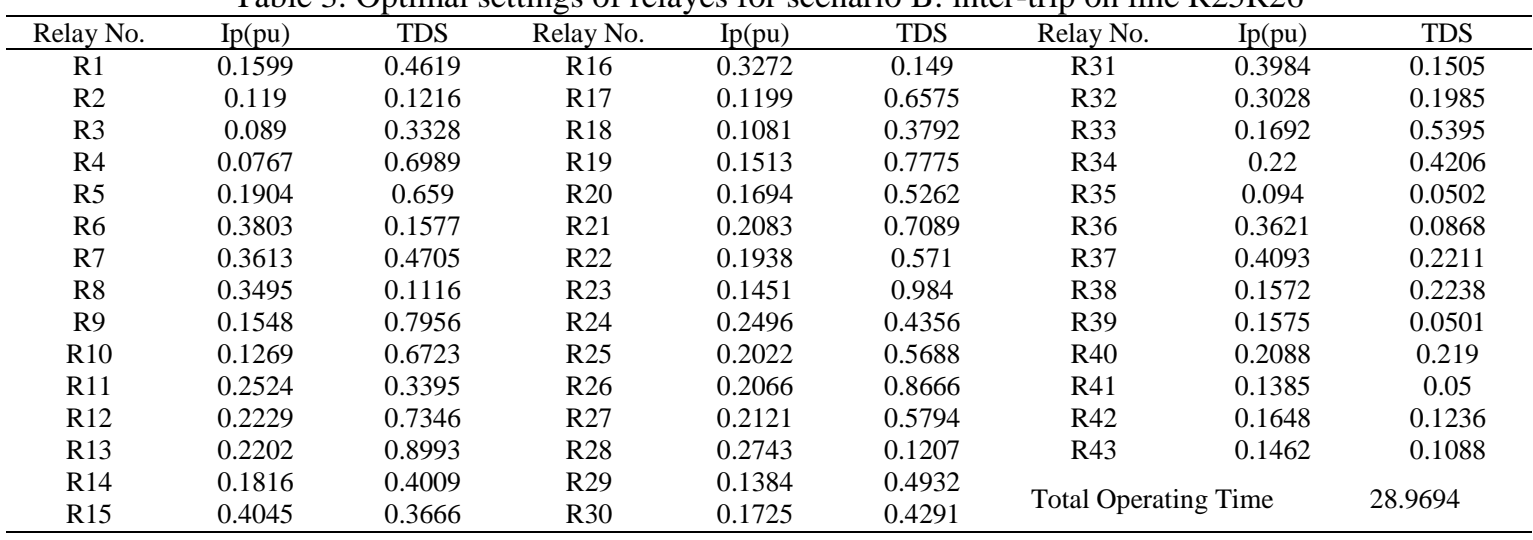

Table 4. Optimal settings of relayes for scenario C: three inter-trip links

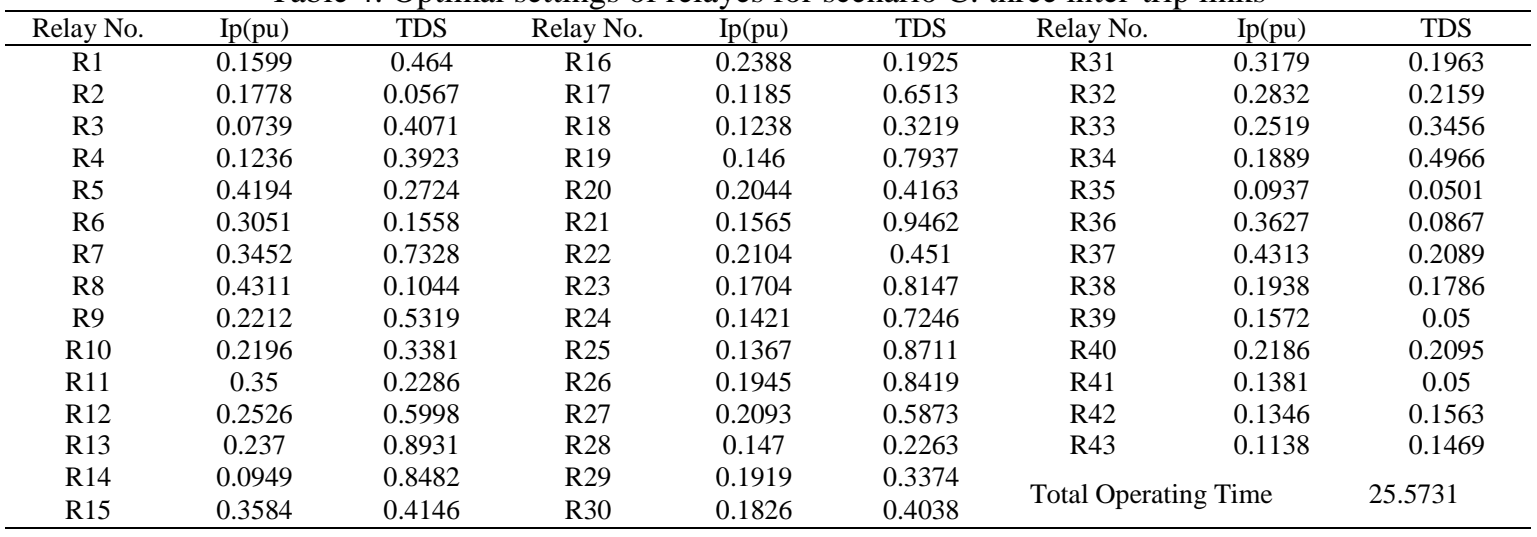

Table 5. Operating time of relays for some faults

\begin{tabular}{ccc}
\hline Fault Location & Primary Relay Operating Time $(\mathrm{Sec})$ & Backup Relay Operating Time $(\mathrm{sec})$ \\
\hline F30 & $0.2917,0.3946$ & $0.4918,0.9432,1.1453$ \\
F43 & $0.1710,0.3200$ & $0.3715,0.7539$ \\
F3 & $0.1325,0.2554$ & $0.3326,2.6389,0.9120,3.0540$ \\
F19 & $0.3067,0.3382$ & $0.5067,0.7090,0.7069$ \\
\hline
\end{tabular}

\section{CONCLUSION}

In this paper, inter-trip links, impact on protection coordination of DOCRs is investigated. It is seen that inter-trip links locally decreases the operating time of relays and the neighbor relays become more sensitive. The proposed index successfully reflects the inter-trip impact and searches for optimum location of inter-trip links. Then, inter-trip links is incorporated in optimal coordination of DOCRs with an optimum allocation feature. The results indicate the capability of proposed index and method, which is verified through the exhaustive search algorithm. 


\section{REFERENCES}

[1] M. Mansour, S. Mekhamer, and N.-S. El-Kharbawe, "A modified particle swarm optimizer for the coordination of directional overcurrent relays,” IEEE Trans. Power Del., vol. 22, no. 3, pp. 1400-1410, Jul 2007.

[2] P. Bedekar, S. Bhide, and V. Kale, "Optimum coordination of overcurrent relays in distribution system using genetic algorithm," Proc. ICPS, pp. 1-6, 2009.

[3] P. P. Bedekar and S. R. Bhide, "Optimum coordination of directional overcurrent relays using the hybrid GA-NLP approach,” IEEE Trans. Power Del., vol. 26, no. 1, pp. 109-119, 2011.

[4] C. So and K. Li, "Time coordination method for power system protection by evolutionary algorithm," IEEE Trans. Ind. Appl., vol. 36, no. 5, pp. 1235-1240, 2000.

[5] M. Barzegari, S. Bathaee, and M. Alizadeh, "Optimal coordination of directional overcurrent relays using harmony search algorithm," in Proc. 9th Int. Conf. EEEIC, pp. 321-324, May 2010.

[6] Ł. Huchel and H. H. Zeineldin, "Planning the Coordination of Directional Overcurrent Relays for Distribution Systems Considering DG," IEEE Trans. Smart Grid, vol. 7, no. 3, pp. 1642-1649, May 2016.

[7] Conti S., Raffa L., and Vagliasindi U, "Innovative solutions for protection schemes in autonomous MV microgrids," Proceedings of the international conference on clean electrical power, pp. 647-654, Jun 2009.

[8] Sortomme E., Venkata S.S., and Mitra J., "Microgrid protection using communication assisted digital relays," IEEE Trans. Power Delivery, vol. 25, no. 4, pp. 2789-2796, 2010.

[9] Prasai A., Yi D., Paquette A., Buck E., and Harley R.G., "Protection of meshed microgrids with communication overlay," Proceedings of the energy conversion congress and exposition (ECCE), pp. 64-71, 2010.

[10] Gao H., Li J., and Xu B., "Principle and implementation of current differential protection in distribution networks with high penetration of DGs," IEEE Trans. Power Delivery, vol. 32, no. 1, pp. 565-574, 2017.

[11] Chang Ying, J. Duan, Sun Lei, He Yu and S. Cui, "Applicability analysis of differential protection for dispersed wind generation in distribution network," IEEE PES Asia-Pacific Power and Energy Engineering Conference (APPEEC, pp. 2148-2152, 2016.

[12] Ustun T.S. and Khan R.H., "Multiterminal hybrid protection of microgrids over wireless communications network," IEEE Trans. Smart Grid, vol. 6, no. 5, pp. 2493-2500, 2015.

[13] Liu X., Shahidehpour M., Li Z. Liu Z., Cao Y., and Tian W., "Protection scheme for loop-based microgrids," IEEE Trans. Smart Grid, vol. 8, no. 3, pp. 1340-1349, 2017.

[14] Dewadasa M., Ghosh A., and Ledwich G., "Protection of microgrids using differential relays," Proceedings of the 21st Australasian universities power engineering conference (AUPEC), Sep 2011.

[15] T. S. Aghdam, H. K. Karegar, and H. H. Zeineldin, "Variable Tripping Time Differential Protection for Microgrids Considering DG Stability," in IEEE Transactions on Smart Grid. vol. 10, no. 3, pp. 2407-2415, May 2019.

[16] M. N. Alam, "Adaptive Protection Coordination Scheme using Numerical Directional Overcurrent Relays," in IEEE Transactions on Industrial Informatics. DOI: 10.1109/TII.2018.2834474.

[17] B. Fani, M. Dadkhah and A. Karami-Horestani, "Adaptive protection coordination scheme against the staircase fault current waveforms in PV-dominated distribution systems," in IET Generation, Transmission \& Distribution, vol. 12, no. 9, pp. 2065-2071, 2018.

[18] S. Asghari Govar, S. Heidari, H. Seyedi, S. Ghasemzadeh, and P. Pourghasem, "Adaptive CWT-based overcurrent protection for smart distribution grids considering CT saturation and high-impedance fault," in IET Generation, Transmission \& Distribution, vol. 12, no. 6, pp. 1366-1373, 2018.

[19] H. F. Habib, C. R. Lashway, and O. A. Mohammed, "A Review of Communication Failure Impacts on Adaptive Microgrid Protection Schemes and the Use of Energy Storage as a Contingency," in IEEE Transactions on Industry Applications, vol. 54, no. 2, pp. 1194-1207, 2018.

[20] M. Singh, T. Vishnuvardhan and S. G. Srivani, "Adaptive protection coordination scheme for power networks under penetration of distributed energy resources," in IET Generation, Transmission \& Distribution, vol. 10, no. 15, pp. 3919-3929, 2016

[21] S. Shen et al., "An Adaptive Protection Scheme for Distribution Systems With DGs Based on Optimized Thevenin Equivalent Parameters Estimation," in IEEE Transactions on Power Delivery, vol. 32, no. 1, pp. 411-419, 2017.

[22] Cintuglu M.H., Ma T. and Mohammed O.A., "Protection of autonomous microgrids using agent-based distributed communication," IEEE Trans. Power Delivery, vol. 32, no. 1, pp. 351-360, 2017.

[23] Nikolaidis V.S., Papanikolaou E., and Safigianni A.S., "A communication-assisted overcurrent protection scheme for radial distribution systems with distributed generation," IEEE Trans. Smart Grid, vol. 7, no. 1, pp. 114-123, Jan 2016

[24] T. S. Aghdam, H. Kazemi Karegar, and H. H. Zeineldin, "Transient Stability Constrained Protection Coordination for Distribution Systems With DG," in IEEE Transactions on Smart Grid, vol. 9, no. 6, pp. 5733-5741, Nov. 2018.

[25] Zeineldin H.H., Sharaf H.M., Ibrahim D.K., and El-Zahab E. E. D., "Optimal protection coordination for meshed distribution systems with DG using dual setting directional over-current relays," IEEE Trans. Smart Grid, vol. 6, no. 1, pp. 115-123, 2015. 